\title{
«CAPÍTULO XI. GOBIERNO DE PONIENTE». HISTORIA DEL REINO DE ARGEL (1733)
}

\author{
TeXto Dispuesto PARA LA IMPRENTA \\ Y EDICIÓN DE IsAac Donoso
}

Reproducimos a continuación edición actualizada del «Capítulo XI. Gobierno de Poniente», del volumen Historia del Reino de Argel; con el estado presente de su Gobierno, de sus fuerzas de Tierra, y Mar, de sus Rentas, Policía, Justicia, Política, y Comercio. Escrita en idioma francés por monsieur Laugier de Tassy, Comisario de la Marina de su Mag. Cristianisima, impresa en Amsterdam el año I725. Traducida en idioma español y adicionada, con la recuperación de Orán, por las gloriosas Armas de España en el año 1732, representada con un Plano, y Perfil de su Plaza, y Castillos, por don Antonio de Clariana y Gualbes, Caballero del Hábito de San Juan, Ėc, Barcelona, Imprenta de Juan Piferrer, I733, pp. I39-I43. Se trata de la versión española del libro Histoire du Royaume d'Alger, avec l'Etat présent de son Gouvernement, de ses Forces de Terre छ de Mer, de ses Revenus, Police, Justice Politique E Commerce. Par Mr. Laugier de Tassy, Ámsterdam, Henri du Sauzet, I725, pp. I49-I53. La versión de Antonio de Clariana (1683-1753) añade una interesantísima y novedosa Disertación sobre la conquista española de Orán de I733, con una detallada descripción de la campaña militar y un croquis de la formación. Reproduciremos en próximos volúmenes esta Disertación que representa el capítulo XII.

\section{$* * *$}

\section{Capítulo Xi.}

\section{Gobierno de Poniente.}

La ciudad de Orán en la costa de Berbería, está situada Norte, y Sur con Cartagena de España. Es la plaza más fortificada de aquel país; distante de Argel 50 leguas hacia al Oeste. 
En el año 1505, reinando Ferdinando V, Rey Católico, en tiempo del Ministerio del Cardenal Ximénez, fue conquistada por los españoles, que la poseyeron hasta el año I708 en que los argelinos la tomaron. Diferentes fortalezas, y castillos, cubren, y defienden la plaza de Orán, tanto de la parte de tierra, como de la del mar.

La España perdía mucho, perdiendo esta ciudad, para las cosas de África, y sus presidios; pues a más que era una escala de comercio, por donde se sacaban un grande número de esclavos, de granos, de aceite, de cueros, de cera, y cantidad de otros géneros, es un freno, y una entrada favorable para ejecutar cualquiera designio contra los argelinos, poseyendo el Rey de España esta plaza, y la rada de Mazalquivir, que en idioma árabe significa Puerto grande; como en efecto está puesto en el número de uno de los buenos puertos; está distante una legua al Oeste de Orán.

Después que los argelinos conquistaron aquella plaza, que ellos tienen, y estiman por de la mayor importancia, pusieron todo conato en conservarla; y el Bey de Poniente, que estaba en Tremecén con toda su corte, puso en Orán su residencia. A más de la guarnición ordinaria, el Bey mantiene siempre con él, y a fu costa, dos mil cololis, nombre con que llaman los hijos de los turcos, y renegados, que se casan con mujeres árabes, o moras, y mil y quinientos moros, que le siguen siempre.

A dos pequeñas leguas al Sur de Orán hay algunos fragmentos de una antigua ciudad, que se llamaba Batha, destruida en el principio del Siglo VII, por las guerras entre los africanos; ahora es sólo de alguna consideración, por una mezquita dedicada en honor del morabuto Cidi-Ben-Zena, cuya memoria tienen en grande veneración. Dicho morabuto ejercía la hospitalidad, y ayudaba a los desvalidos. Vivía solitario, entre las ruinas de dicha ciudad, aguardando que viese pasajeros, y descubriendo alguno, que le pareciese necesitado, le conducía a su cueva, le regalaba con pan, y frutas, le hospedaba, y le hacía rogar a Dios; y en este acto de caridad, no diferenciaba amigos, o [I4O] enemigos, porque a todos igualmente dispensaba sus socorros. El Morabuto fue recompensado del cielo, pues fueron tan considerables las limosnas, y riquezas de ganados, y bienes que adquirió, que con ellas mantenía quinientos discípulos, a quienes obligaba a rezar en ciertas horas los atributos de Dios; y ha dejado una secta, que 
aun hoy dura, aunque poco numerosa. Los árabes llaman a este lugar, el Llano de Zena, por el nombre del morabuto.

La ciudad de Tremecén, que se llamó antiguamente Telimicen, era la capital del reino, más grande, que había en la Mauritania Cesariense; está a ro leguas del mar, y a 25 de Orán; sus muros son bastantemente buenos, y flanqueados con torreones; tiene cinco puertas, con sus puentes levadizos, y algunas fortificaciones suficientes para defenderla contra los reyes vecinos del Reino de Argel; pero ahora no se ven más en ella, que tristes memorias de aquella ciudad, de que los antiguos historiadores hablaron con tanta pompa, y distinción; y en la cual las ciencias, y las artes en tanto auge florecieron. Está poblada, como las demás ciudades del Reino de Argel, de pobres árabes, de moros, y de judíos. Hay en ella siempre buena guarnición de soldados. El Bey de Poniente hacía en ella su residencia, menos en [I4I] el tiempo que han ocupado Orán. El territorio de Tremecén confina con las montañas del Grande Atlas, que separan el Reino de Argel, del de Fez. Es Tremecén ciudad muy recomendable a los moros, a causa de un sepulcro, que hay en su vecindad, en el cual está enterrado un morabuto llamado Cidi-Ben-Median, a quien atribuyen milagros. En el distrito, y comarca de Tremecén, había antes hermosas, y grandes ciudades, que ahora sólo son pequeñas, y miseras aldeas.

Mostagan es una pequeña ciudad a i5 leguas al Este de Orán, no tiene cosa memorable, más que un buen puerto de mar, defendido por una fortaleza, que domina también la ciudad. Cerca de Mostagan está el Monte-Magarava, que se extiende unas diez leguas, Este, y Oeste. Ha tomado el nombre de la nación de los árabes que lo habitan, a los cuales llaman magarabes, que descienden de los zenetes, y originariamente de los bereberes.

Tenez es una ciudad a siete leguas al Este de Mostagan, situada sobre el declivio de una montaña, a una legua distante del mar, en donde hay un puerto. Esta ciudad, y sus comarcas eran antiguamente de la dependencia del Reino de Tremecén; pero después hubo un rey de Tenez, independente del de Tremecén; ahora no es ciudad [I42] considerable. Los argelinos tienen en ella guarnición, y su país abunda mucho en granos, en miel, en cera, $y$ en ganados. 
144 IsAac Donoso

Serceles es una pequeña ciudad arruinada, en la orilla del mar, a ocho leguas al Oeste de Argel; hay en ella guarnición, y un puerto, para las pequeñas embarcaciones.

Aqui acaba Monsieur Laugier de Tassy, su primer libro; y ha parecido adicionarlo con la Disertación siguiente. 


\section{H I S T O R I A \\ D E L}

\section{REYNO DE ARGEL;}

CON EL ESTADO PRESENTE DE SV, Govierno, de fus fuerças de Tierra, y Mar, de fus Rentas, Policia, Jufticia, Politica, y Comercio.

ESCRITA EN IDIOMA FRANCES,

POR MONSIEVR L A V GIER DE TASSY; Comiffario de la Marina de fu Mag. Chriftianiffima, impreffa en Amfterdàm el año a 725. Traducida en idioma Efpañol,y addicionada, con la recuperacions de Oràn, por las gloriofas Armas de Efpana en el año I 732. reprefentada con vn Plano, y Perfil de fu Plaça, y Caftillos.

$$
\text { P O } \mathbf{R}
$$

DON $A T T O N I O$ DE CIARI y Gualbes, Cavallero del Abito de San fwan, oce.

\section{BARCELONA MDCCXXXIII.}

En la Imprenta de JVAN PIFERRER, à la Plaç del Angel. CON LICENCIA, $\Upsilon$ PRIVIKEGIO. 


\section{HISTOIRE DU ROYAUME}

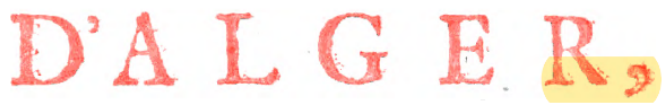

Avec l'Etat préfent de fon Gouvernement," de fes Forces de Terre \& de Mer,de fes. Revenus, Police, Juftice Politique \& Commerce. -P A R

MR. LAUGIER DE TASSIV,

Commifaire de la Marine, pour S A M AIESTE' TRES-CHRETIENNE, en Hollande.

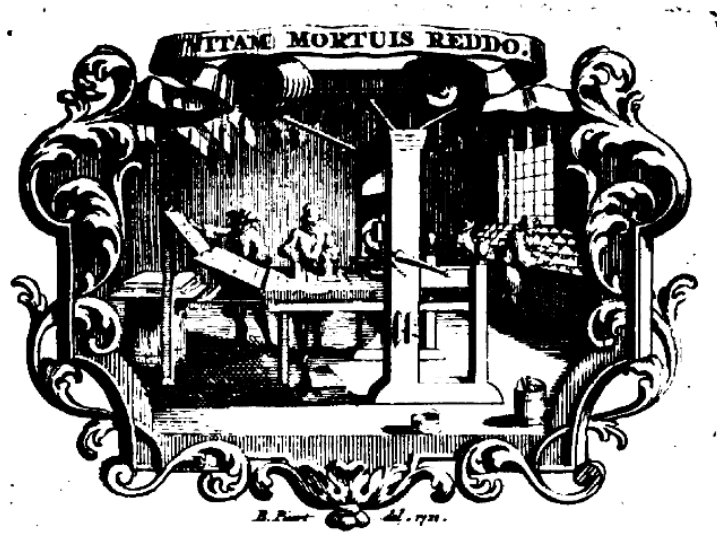

A ANSTER DAM,

Che HENRI DU SAUZE I.

M. DCC. XXV. 